\title{
LAS FUENTES LITERARIAS DEL MACÍAS EN PORFIAR HASTA MORIR, DE LOPE DE VEGA
}

\author{
Irene González, Muñoz
}

\begin{abstract}
RESUMEN
En este artículo se realiza un estudio sobre las fuentes literarias y legendarias de Macías, el trovador gallego de finales del siglo XIV, cuya fama y tradición han sido de las más reelaboradas dentro de la literatura española, no sólo por sus contemporáneos, sino también por autores posteriores. El estudio de esta tradición obedece, sobre todo, al interés por comprender la comedia de Lope de Vega Porfiar Hasta Morir, la cual el Fénix compuso tomando como pre-texto la leyenda de Macías, El Enamorado.

Palabras clave: Macías, Lope de Vega, Porfiar hasta morir, literatura española.
\end{abstract}

\begin{abstract}
This article presents a study concerning the literary sources and legends of Macías, a Galician troubadour of the end of the 14th century, whose fame and traditions have been one of the most documented within Spanish literature, not only by his contemporaries but also by later authors. The study of this tradition closely follows, over all, an interest in understanding the comedy of Lope de Vega, "Persistence until Death" in which the Phoenix is to be taken as pre-text to the legend of Macías, The Lover.

Key words: Macías, Lope de Vega, Persistence until Death, Spanish literature.
\end{abstract}

Irene González Muñoz. Profesora de Estudios Generales, Universidad de Costa Rica. San Pedro, San José, Costa Rica

Recepción: 12-07-04

Aceptación: 13-07-04 
"Porque es imposible aprender a comprender y a gustar un modo de expresión poética, sin comprender y sin participar del espíritu que lo creó.”

Alicia C. de Ferraresi

En su obra, Jorge Manrique o tradición y originalidad (1952), Pedro Salinas afirma que la tradición es una "grandiosa totalidad" que rodea al escritor y penetra en él como el aire que se respira, y debe ser considerada como la fuente primaria de la cual se nutre el poeta para su trabajo creador, pues "es la enorme reserva de materiales con los que el hombre puede rodearse de horizontes" (Salinas 1952: 123). Por esto, no comprende cómo algunos la conciben como una traba que sujeta la originalidad del artista, y plantea, además, que, por el contrario, la tradición ofrece al poeta la libertad de escoger la parcela de ella (acto que no concibe ni deliberado ni conciente) que le permitirá llevar a cabo su obra creadora.

En este mismo sentido, Salinas plantea que la "tradición consiste en tener presente ante la conciencia el pasado literario, sobre el cual pueda actuar libremente el artista aprovechándose de aquel o aquellos impulsos, de los muchos que contiene en su haz la tradición, que mejor le ayuden a la realización de su obra" (Salinas 1952: 135). De esta manera, la selección que el escritor hace del material que la tradición le brinda no supone ni la copia ni la burda imitación, sino la oportunidad de nutrir aún más la misma tradición cuando este creador le añada lo suyo. Así, la nueva obra se convertirá, a la vez, en parte de la tradición.

Siguiendo con este pensamiento, Salinas cita a Lowes en su obra Convention and Revolt in Poetry (1926), quien propone que existen tres actitudes para enfrentar la convención literaria. La primera es una actitud mimética: el poeta se conforma y acepta la tradición pasivamente; es decir, se limita a repetir el modelo que ésta le ofrece. Este es, según Salinas, el caso del poeta neoclásico puro, que si bien no añade nada a la tradición, al menos la mantiene. En la segunda actitud, el poeta conserva la tradición, pero a la vez la moldea para construir una nueva obra, la utiliza como un principio ordenador. En este caso, no existe el afán mimético, sino el creativo, pues el "proceso de composición consta de un conjunto de reproducciones de estos o aquellos elementos suministrados por la tradición; sin embargo, la operación total que abarca todas esas operaciones repetitorias menores es de carácter creador, y su producto, original" (Salinas 1952: 137). Y la tercera y última actitud ante la tradición consiste en desestimarla en el proceso creador; sin embargo, esto no quiere decir que la suprima por completo, pues sería como borrar el pasado.

Precisamente, es la segunda actitud la que Félix Lope de Vega adoptó para producir su obra dramática Porfiar hasta morir (1638), comedia cuya verdadera importancia ha sido soslayada por la crítica, y en la que se exaltan no sólo los ideales del amor cortés, rica tradición literaria que en España se remonta por lo menos al siglo XIII, sino también la leyenda del trovador gallego Macías, El Enamorado. La comedia presenta los frustrados amores de este personaje, que en la Península encarna el prototipo del enamorado cortés a un tiempo histórico y legendario.

En el primer acto de la comedia, conocemos a Macías, hidalgo castellano que, decidido a abandonar sus estudios para dedicarse a las armas, viaja a Córdoba con Nuño, su criado, para entrar al servicio del maestre de Santiago. Antes de llegar a Córdoba, se 
ve involucrado en un incidente en el que le salva la vida a un caballero, el cual queda en deuda con Macías. Más tarde, nuestro protagonista se entera de que el desconocido no es otro que el propio maestre de Santiago. Aclarada la identidad de este caballero, Macías y Nuño se dirigen a casa del maestre, quien, sin pensarlo dos veces, lo acepta como uno de sus servidores.

Es precisamente en casa del maestre que Macías conoce a Clara, de quien se enamora "a primera vista" y a quien promete amar y servir "lo que [le] durare la vida...", aún después de saber que Clara ya está desposada con Tello de Mendoza, el privado del maestre. Debido a que su amor por esta dama no es correspondido, Macías se va a la guerra contra el rey Almanzor, en busca de la muerte como único remedio para aliviar su pena.

El segundo acto se inicia con el victorioso regreso de Macías, quien ha probado ser un valiente soldado en la batalla, razón por la cual el rey Enrique decide premiarlo con lo que él desee, lo que Macías aprovecha para pedir que se le otorgue la mano de Clara. El rey le dice que eso es imposible y en su lugar le otorga hacerlo caballero de Santiago. Ante la imposibilidad de lograr sus amores, el joven empieza a escribir romances y canciones en los que expresa su dolor y sus celos, convirtiéndose en un poeta de ingenio. Clara y Tello contraen matrimonio y Macías llega a tal grado de desesperación, que la noche de bodas se la pasa en vela tramando cómo interrumpir el idilio de los recién casados.

En el tercer y último acto, Tello pide al maestre que ponga un alto a Macías, pues tiene miedo de que su mujer sucumba ante la porfía de este enamorado, quien continúa escribiendo canciones, que ya todos repiten, en las que pregona abiertamente su amor por Clara. Mientras el preocupado marido hace esta petición, Macías sigue acosando personalmente a Clara, quien preocupada por su fama, lo conmina a escribir sobre otros temas y no sobre ella.

Debido a la gravedad de la situación, el maestre decide encarcelarlo, más por protegerlo de la furia de Tello, que por guardar el honor de su privado. Pero ni la cárcel pudo contenerlo, pues en ella sigue escribiendo sus poemas. Tello ya no puede soportar y, en concierto con Páez, otro caballero al servicio del maestre, decide matar a Macías arrojándole una lanza a través de los barrotes de la celda. A pesar de que ya moribundo Macías reconoce su falta y perdona a Tello, el maestre le promete vengarse y dejar testimonio de que su amor fue 'honesto' y 'verdadero', asegurándole que en su sepulcro dirá "aquí yace el mismo amor".

Según don Marcelino Menéndez Pelayo (1949), es difícil establecer una clasificación metódica y racional de la producción dramática de Lope, debido a lo extenso de su obra (de la cual se conservan alrededor de 470 comedias), en la que se encuentran los más variados rasgos de estilo, acción, calidad de los personajes, características épicas o líricas, etc. Un criterio cronológico tampoco sería suficiente, pues son relativamente pocas las comedias que cuentan con fecha y menos aún aquellas que se pueden fijar en el tiempo gracias a otros datos, ya sea intrínsecos o extrínsecos. Además, el mismo Lope nunca empleó un criterio cronológico al hacer la lista de sus comedias.

Ante este panorama, Menéndez Pelayo propuso para la edición de las obras completas de Lope que hiciera la Academia Española, a fines del siglo XIX (1890), una clasificación por géneros o asuntos, la cual se considera hasta hoy como la más acertada y funcional para el estudio crítico de la producción dramática de este autor. Esta clasificación es la siguiente: 
Piezas cortas Comedias religiosas \{

-autos, coloquios, loas y entremeses

a. Comedias fundadas en asuntos del Antiguo Testamento

b. Comedias fundadas en asuntos del Nuevo Testamento

c. Comedias de vidas de Santos y otras personas piadosas

d. Comedias fundadas en leyendas o tradiciones devotas

e. Comedias mitológicas (Oriente, Grecia y Roma)

f. Comedias sobre argumentos de la historia clásica

g. Comedias de historia extranjera

h. Comedias de recuerdos y tradiciones de la historia patria

[Comedias profanas $]^{1}$

i. Comedias pastoriles

j. Comedias caballerescas

k. Comedias extraídas de novelas italianas

l. Comedias románticas (o de enredo) ${ }^{2}$

m. Comedias de malas costumbres

n. Comedias de costumbres urbanas y caballerescas

o. Comedias aristocráticas o palatinas

Interesa referirnos a las comedias de recuerdos y tradiciones de la historia patria, también llamadas por Zamora Vicente de crónicas y leyendas dramáticas de España, apartado que se subdivide con un criterio cronológico que comprende desde el período visigótico hasta la época contemporánea de Lope (Felipe III y Felipe IV). Quienes se han dedicado al estudio del teatro del Fénix coinciden en afirmar que "Lope exaltó dramáticamente todas las tradiciones posibles, todas las convicciones y supuestos del español de su tiempo" (Zamora 1961: 192) y es precisamente en este eje temático en donde se ubican algunas de sus mejores creaciones, entre ellas, Porfiar hasta morir. Lo anterior contrasta con la tradición en el sentido de que el personaje Macías aparece, generalmente, en poemas de distintos autores como se verá adelante y, en el caso de Lope, nos encontramos con el primer autor dramático que monta una comedia completa cuyo protagonista es Macías. En la clasificación de Menéndez Pelayo, y dentro de la producción del propio Fénix, esta es la única obra en que Macías se constituye en el pre-texto de la trama.

El argumento de esta comedia se basa en la tradición del trovador gallego Macías, El Enamorado, al que Ermitas Penas Varela (1992: 72) considera "una figura desconocida en un estricto sentido histórico", pues todo lo que se sabe del personaje es oscuro e incierto. No obstante, conocemos algo de su producción poética, recogida en el Cancionero de Baena: 
(Folio 108)

Cantiga de Macías para su amiga.

Cativo de miña trystura,

Ya todos prenden espanto

E preguntan ¿qué ventura

Foy que me tormenta tanto?

(Folio 108 vuelto)

Cantiga de Macías para su amiga.

Señora, en que fiança

He por cierto syn dubdança,

Tú non ayas por vengança

Mi tristura (Baena 1949: 345-6)

Quien mejor estudia las fuentes de Porfiar hasta morir es don Marcelino Menéndez Pelayo. Según sus investigaciones, Macías era gallego de nacimiento, como lo asegura en Los siete gozos de amor Juan Rodríguez del Padrón, coetáneo y gran admirador del trovador:

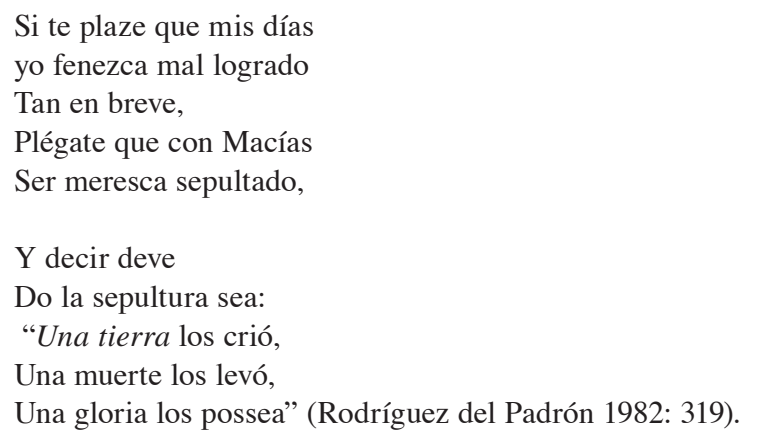

Antonio Prieto (1976), en el prólogo a la edición crítica de Siervo libre de amor, afirma que Macías es el personaje que caracteriza la trayectoria de Rodríguez del Padrón dentro del amor cortés, según se deduce de las constantes alusiones que este escritor hace del trovador gallego en sus poesías, pues, aparte de considerarlo gran poeta, como se comprueba en el verso "una gloria los posea", también lo toma como modelo del mártir de amor. Así lo deja ver en los versos que escribe al final de esta obra.

Pues que Dios y mi ventura

m'atraydo a tal estado,

cantaré con grand cuydado.

Catyvo de mi tristura.

No se que postremería

ayan buena los mis días,

quando el gentil Macías

priso muerte por tal vía.

Por ende, en rremembrança

cantaré con amargura: 
Cuydados y maginança,

catyvo de mi tristura.

Los que me vieren asy

no ayan a maravilla

mi grave cuyta y manzilla,

que tal señora perdy.

Por lo cual tribulança

cantaré con amargura:

Ya, señora, en quien fiança,

catyvo de mi trystura (Rodríguez del Padrón 1976: 110-1) .

Se han resaltado en negrita los versos que recuerdan las cantigas de Macías, cuyas características o rasgos esenciales son las cuitas de amor; es decir, versos que cantan al dolor y a la desgracia del enamorado no correspondido, como se evidencia en las dos estrofas finales de la cántiga que hizo Macías en Loores del Amor:

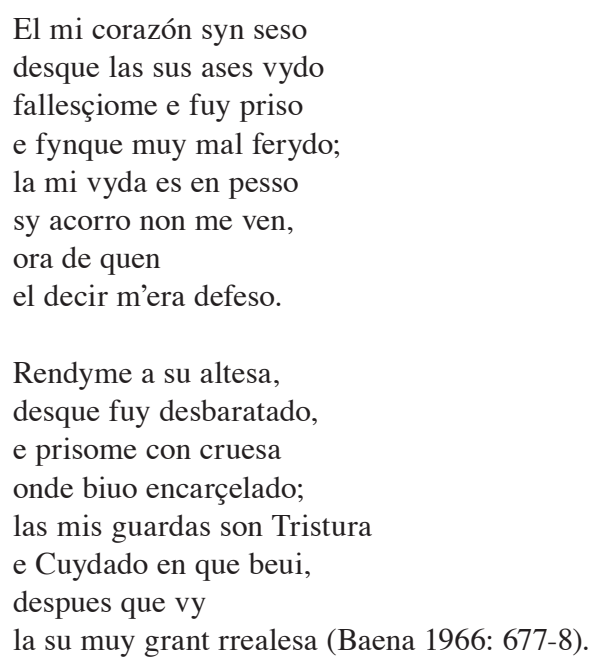

Como modelo de enamorados, Macías, su leyenda y su obra sirvieron de pre-texto para otros poetas del medioevo español, entre ellos, el marqués de Santillana, quien lo utiliza como personaje en su obra Infierno de los enamorados. En este poema, Macías junto con otros célebres enamorados clásicos: Paris y Thesena, Eneas y Dido, Aquiles y Policena y otros, se encuentra en el limbo.

\author{
muy paso me fui llegando \\ a dos que vi rrazonando \\ que en nuestra lengua fablavan. \\ [...] \\ Dezidme ¿de qué materia \\ trata[des] después del lloro \\ en este linbo [e] miseria, \\ do Amor faze su thesoro? \\ asymesmo vos inploro \\ que sepa yo do naçistes,
}


e ¿cómo o quando venistes

en [el] miserable coro?

[...]

[E] si por ventura quieres saber por qué soy penado plázeme, porque si fueres al tu siglo trasportado, digas que soy condenado por seguir d'Amor sus vías; e finalmente Macías en Espa[ñ]a fuy [nombrado] (Santillana 1975: 224-6).

Al colocar a Macías en el mismo nivel en que se hallan los amantes clásicos, Santillana le adjudica el rango de arquetipo mítico, convirtiéndolo por antonomasia en el poeta enamorado y en modelo para ser imitado.

En el poema colectivo Querella de amor, en el que se introducen versos de otros autores, Santillana inserta algunas estrofas que pertenecen a Macías:

o[í] triste cantinela,

que tal canción pronunciava:

"Amor cruel e bryoso,

mal aya la tu alteza,

pues no fazes igualeza,

seyendo tan poderoso" (Santillana 1975: 139).

La estrofa en cursiva es la que da inicio a la Cantiga contra el Amor, de Macías. Otra estrofa empleada por Santillana es la que se ha citado anteriormente en este estudio: "Cativo, de miña tristura/ya todos prenden espanto...", de la "Cántiga de Macías para su amiga".

Otro poeta del siglo XV, Juan de Mena, en su Laberinto de Fortuna, le dedica las coplas CV, CVI, CVII y CVIII, las cuales forman parte de la descripción del tercer círculo (el de Venus), en donde se encuentran los amadores del amor virtuoso:

Tanto anduvimos el cerco mirando, que nos fallamos con nuestro Macías, y vimos que estava llorando los días con que su vida tomó fin amando.

$[\ldots]$

y vi que dezía tal triste canción

su elegíaco verso cantando:

"Amores me dieron corona de amores porque mi nombre por más bocas ande. Estonces non era mi mal menos grande cuando me davan plazer sus dolores" (Mena 1976: 98-9).

En estas coplas, no solo se nos presenta a Macías como prototipo del amante virtuoso, sino también como un 'coronado' mártir de amor, según se deduce de los versos "Amores me dieron corona de amores $[. .$.$] / cuando me davan plazer sus dolores".$ 
En la poesía amatoria de Gómez Manrique también se hace mención a Macías. En su poema "Lamentación", en el que el amante expresa su dolor por la separación de su amada, se cita a Macías como ejemplo de la víctima de amor:

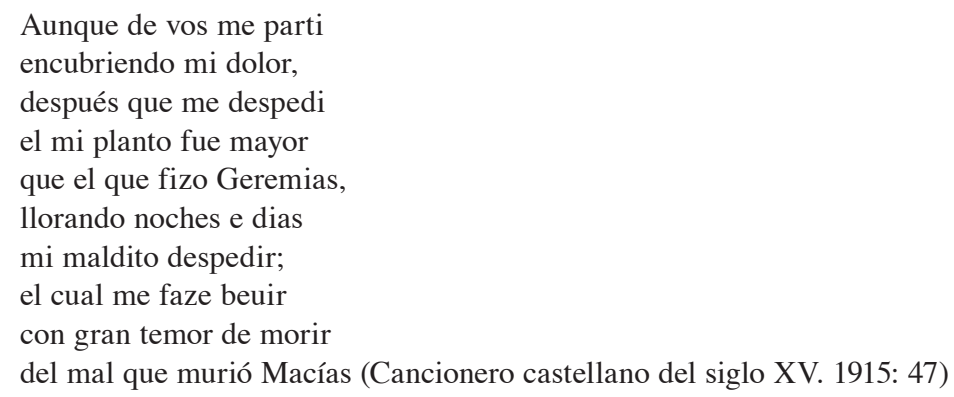

Garci Sánchez de Badajoz lo menciona en las Lecciones de Job, cuando el yo poético, preparado para morir de amor, se dispone a escribir su "postrera voluntad".

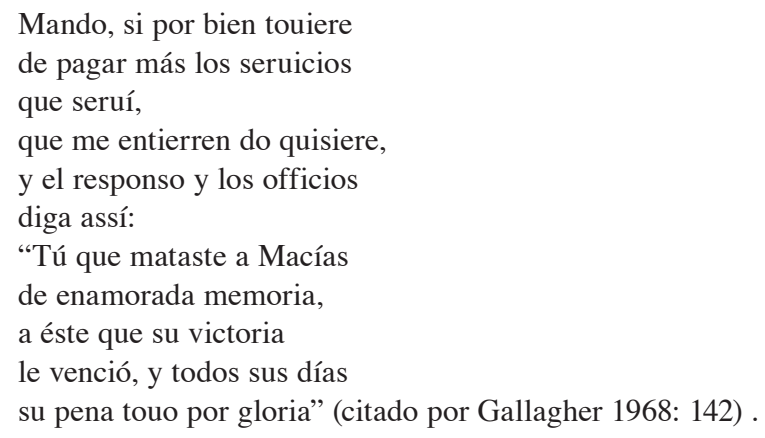

Es interesante anotar la identificación que se establece entre la leyenda de Macías y la vida de Sánchez de Badajoz. Según testimonios de algunos de sus contemporáneos, este poeta se había enamorado de una prima que no le correspondió, razón por la cual él enloqueció de amor y se suicidó. Otros afirman que su locura fue un castigo divino por la herejía cometida al profanar las Sagradas Escrituras en las Lecciones de Job. Para Patrick Gallagher, "the traditional explanation of Garci Sánchez's madness might first have been propagated by the poet himself, anxious to invite comparisons with the tragic Macías" (1968: 11) y, de esta manera, ser recordado como mártir de amor.

Según hemos visto, a pesar de que Macías es —históricamente- un personaje oscuro, su fama de desventurado amador cortés, causada en gran parte por la interpretación autobiográfica de sus cantigas de amor, no corre la misma suerte:

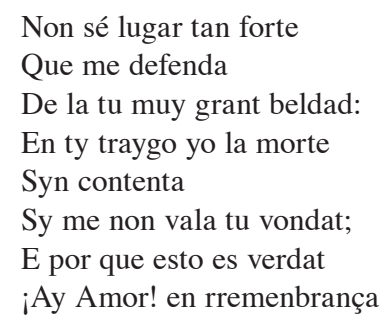


En meu cor tengo tu lança

De amargura (Baena 1949: 345).

Por el contrario, esta fama de amante desgraciado (evidente en sus poemas) todos los autores mencionados la recuerdan, la celebran y reconocen su producción poética como modelo textual. Además, es fama que aumenta con los mitos póstumos con los que se ha querido explicar la causa de su muerte y con las creaciones poéticas de sus seguidores. Cabe señalar, además, como ya lo hiciera doña Alicia C. de Ferraresi (1976), en De Amor y Poesía en la España Medieval: Prólogo a Juan Ruiz, que la poesía amatoria española se nutre de la tradición de la "cantiga d'amor" galaico-portuguesa, la cual a su vez se inspira en la lírica del Languedoc, tradición en la que se canta no solo a la queja de amor, sino también al júbilo amoroso; pero "por mucho que a ésta deba la galaico-portuguesa, no le debe por cierto su joi. Al componer a "maneira de proençal" [sic.], el trovador gallego cantaba no el júbilo amoroso, sino la "coita", el dolor de amar" (de Ferraresi 1976: 6). Precisamente, a este hecho se puede atribuir el éxito de Macías en la tradición de la poesía amorosa española, pues, como ya se ha mostrado, es el arquetipo del amante desgraciado.

Como ya se ha dicho, don Marcelino Menéndez Pelayo es quien determina cuáles son las fuentes de la leyenda del trovador. Según sus investigaciones, la versión más antigua que se conoce - 1450 a 1453 - es la del condestable don Pedro de Portugal, quien en una glosa a su Sátira de felice e infelice vida dice que Macías era un joven gallego que se enamoró de una doncella a la que salvó de morir ahogada. Más tarde, esta joven contrae matrimonio, lo que no es impedimento para que el trovador siga con su servicio amoroso, razón por la cual lo asesina el celoso marido cuando el propio Macías le confiesa el amor que siente por la dama. Sin embargo, es la versión del Comendador Griego Hernán Núñez, con la cual glosa la copla CV del Laberinto de fortuna de Mena, retocada luego por Argote de Molina, la que sirve como base para la trama de Porfiar hasta morir.

Según la versión de Hernán Núñez, Macías era un gentilhombre que, encontrándose al servicio del maestre de Calatrava, se enamora -sin ser correspondido- de una doncella que también servía en casa del maestre. Más tarde, la joven contrae matrimonio con otro caballero, lo cual no impide que Macías continúe su servicio amoroso. Esto provoca los celos del agraviado marido, quien pide al maestre poner fin a esta situación. Macías es reprendido por su señor; aún así, sigue adelante con su propósito de servir a la dama, por lo cual es encarcelado. Una vez en prisión, el marido celoso, en concierto con el carcelero, hace un hoyo en el tejado de la celda y por él arroja una lanza con la que mata al trovador. Macías es enterrado en Arjonilla, Andalucía.

La versión de Argote de Molina sigue las mismas líneas de la del Comendador, agrega otros datos y varía la leyenda en un punto esencial. Según Argote, el maestre de Calatrava es don Enrique de Villena y Macías sí es correspondido por su amada, a la que el maestre casa —en ausencia del trovador - con otro caballero. El hecho de que la dama corresponda a Macías, da pie para que él escriba y le envíe cartas y canciones de amor. El marido se entera y recurre al maestre, quien en su deseo de evitar problemas lleva preso a Macías a Arjonilla. Desde su encierro éste sigue enviando notas a su amada. Finalmente, la cólera y los celos del marido lo inducen a matar a su rival, arrojándole la lanza a través de una ventana, en la que se encontraba el amante lamentándose de su suerte. Macías es sepultado en la Iglesia de Santa Catalina, en Arjonilla. Sobre su tumba se colocó la lanza y se escribieron los versos tomados de una de las cantigas que se atribuyen a Macías: 
Aquesta lança syn falla,

¡Ay coytado!

Non me la dieron del muro,

Nin la pryse yo en vatalla.

¡Mal pecado!

Mas veniendo á ty seguro,

Amor falso é perjuro

Me firió é syn tardança,

E fue tal la mi andança,

Syn ventura (Baena 1949: 345).

Como ya hemos citado, Menéndez Pelayo afirma que Lope se inclina más por la versión de Argote de Molina. Penas Varela refuta esta tesis alegando, básicamente, que en la comedia Macías no es correspondido por la dama, sino todo lo contrario, como sucede en la versión del Comendador Griego, y que, por lo tanto, ésta es la que sigue el Fénix. Conforme nuestra lectura de la obra, no es posible asegurar, al menos tajantemente, que Clara no corresponde a Macías, pues en alguna medida lo hace, no solo al aceptar las cartas que él le envía, sino también porque así se colige de las palabras de la misma Clara.



Además, en la versión de Argote de Molina, Macías escribe cartas y canciones de amor para su amada, como lo hace el protagonista en la comedia de Lope lo que, en ambos casos, es la causa del fatal desenlace. Otra semejanza entre la leyenda y la comedia es el hecho de que al morir Macías, se decide poner un epitafio sobre su tumba. En el caso de la leyenda se utilizan los versos oportunamente mencionados, mientras que en la comedia el epitafio reza "Aquí yace el mismo Amor".

Por lo anterior, es evidente que la versión que más se ajusta a la trama de la comedia de Lope de Vega es la de Argote de Molina, según ya lo había asegurado Menéndez Pelayo.

Establecida la fuente primaria de la leyenda de Macías, cabe destacar que los distintos textos en que Macías es citado, pertenecen al género lírico y son creaciones poéticas en las que el yo lírico canta las "cuitas" de amor de este trovador, que se nos presenta entonces como el enamorado por excelencia, que canta a su dolor, el cual considera justa paga a su amor no correspondido: "Amores me dieron corona de amores .../cuando me davan plazer sus dolores" (Mena 1976: 99).

Realizar un estudio de las fuentes que nutren una obra literaria es una tarea necesaria cuando se pretende conocer no solo a un poeta, sino también la corriente de pensamiento de la época en que se produce una obra determinada. Así, con el caso de la tradición de Macías en la literatura española, conocemos, por una parte, el origen de su leyenda como mártir de amor y como modelo de enamorados, lo cual se atribuye más a la 
fama que estos poetas citados anteriormente le confieren, que a su producción literaria; pero también, por otra parte, la investigación nos permite comprender mejor el texto de Lope de Vega, quien es el primero que le dedica a Macías una obra entera en la que se dramatiza su tragedia, a saber, la comedia Porfiar Hasta Morir, en la que se desarrolla la historia de este amante cortés.

\section{Notas}

1. A pesar de que Menéndez Pelayo incluye todas estas comedias dentro de la categoría de Comedias religiosas, la autora de este trabajo prefirió, por oposición, clasificar las comedias de la e. a la o. como profanas.

2. Comedias de enredo es como las llama Alonso Zamora Vicente.

\section{Bibliografía}

Aguirre, José Luis. 1961. Lope de Vega y su obra. Tomo II. Valencia: Cosmos.

Alborg, Juan Luis. 1980. Historia de la literatura española. Tomo II. Madrid: Editorial Gredos.

Baena, Juan Alfonso de. 1949. El cancionero de Juan Alfonso de Baena. Buenos Aires: Anaconda.

1966. Cancionero de Juan Alfonso de Baena. Tomo II. Edición crítica de José María Azaceta. Valencia: Clásicos Hispánicos.

Cancionero castellano del siglo XV. Tomo II. (NBAE) 1915. Edición de Ramón FoulchéDelbosc. Madrid: Casa Editorial Bailly-Bailliere.

C. de Ferraresi, Alicia. 1976. De Amor y de Poesía en la España Medieval: Prólogo a Juan Ruiz. México: Colegio de México.

Del Enzina, Juan. 1968. Églogas completas de Juan del Enzina. Edición crítica de Humberto López Morales. New York: Las Americas Publishing Company.

Gallagher, Patrick. 1968. The Life and Works of Garci Sánchez de Badajoz. London: Tamesis.

Lapesa, Rafael. 1957. La obra literaria del Marqués de Santillana. Madrid: Insula. 
Lowes, John Livingston. 1926. Convention and revolt in poetry. Boston/New York: Houghton Mifflin Company.

Marqués de Santillana. 1975. Poesías completas I. Edición crítica de Manuel Durán. Madrid: Castalia.

Mena, Juan de. 1976. Laberinto de Fortuna y poemas menores. Edición crítica de Miguel Ángel Pérez. Madrid: Editora Nacional.

Menéndez Pelayo, Marcelino. 1949. Edición nacional de las obras completas. Vols. 8, 29, 33. Dirigida por Angel González Palencia. Santander: Aldus S. A.

Penas Varela, Ermitas. 1992. Macías y Larra. Tratamiento de un tema en la novela. Santiago de Compostela: Imprenta Universitaria.

Rodríguez del Padrón, Juan. 1976. Siervo libre de amor. Edición crítica de Antonio Prieto. Madrid: Castalia.

Rodríguez Sánchez, Tomás. 1986. "Macías en la literatura española.” En: Homenaje a Pedro Sainz Rodríguez. Tomo II. Madrid: Fundación Universitaria Española.

Ruiz Ramón, Francisco. 1988. Historia del teatro español (Desde sus orígenes hasta 1900). Madrid: Cátedra.

Salinas, Pedro. 1952. Jorge Manrique o tradición y originalidad. Buenos Aires: Editorial Sudamericana.

San Pedro, Diego de. 1984. Obras completas. Vol. II. Edición crítica de Keith Whinnom. Madrid: Castalia.

Scholberg, Kenneth R. 1984. Introducción a la poesía de Gómez Manrique. Madison: The Hispanic Seminary of Medieval Studies, Ltd.

Valbuena Prat, Angel. 1969. El teatro español en su Siglo de Oro. Barcelona: Editorial Planeta.

Vega, Lope de. 1886. Obras escogidas de Frey Lope Félix de Vega Carpio. Tomo I. París: Casa Editorial Garnier Hermanos.

Zamora Vicente, Alonso. 1961. Lope de Vega. Su vida y obra. Madrid: Editorial Gredos. 